\title{
The establishment and practice of "informatization surveying" practical teaching system of surveying and mapping engineering
}

\author{
Yuan zhanliang $^{1, \mathrm{a}}$,Qi xiudong ${ }^{1, \mathrm{~b}}, \mathrm{Xu} \mathrm{keke}^{1, \mathrm{c}}$,Wang yanan ${ }^{1, \mathrm{~d}}$ \\ School of surveying and mapping, henan polytechnic university, henan, 454000,china \\ aEmail:yuan6400@hpu.edu.cn
}

Keywords: surveying and mapping engineering; informatization; practical teaching; talent training

\begin{abstract}
The paper is based on the education practice of undergraduate major of surveying and mapping engineering for years, analyses the present and future social needs of this major, quality and ability of students of surveying and mapping engineering major which are demanded by employing units, and accelerates the teaching reform and enhance the higher education quality of surveying and mapping engineering. Determining the training goal of innovative talents of surveying and mapping engineering major in a new era, and recognizing the two ability that practice and innovation are the core of professional talent training, defining the two practical platforms that intramural simulation and extramural combat are the effective carrier of the two ability cultivation, constructing and innovating "informatization surveying" practical teaching system of "seriation, three-dimensional, multi-level" is the effective way of completely improving surveying and mapping talents.
\end{abstract}

\section{Introduction}

With the rapid development of informatization technology, surveying and mapping subject has a rapid development in theory and technology, the new technique that digital surveying, GNSS surveying, digital photogrammetry surveying, 3D laser scanning, remote sensing satellite surveying are emerging. The era of digital and informatization surveying has already come[1]. At present, the flourishing development of surveying and mapping undertaking promotes the rapid progress of related science and technology in our country, the society urgently needs a large number of applied professional talents with practical ability and innovative ability who can undertake surveying tasks and continuously develop new technique and new process with the changes of environmental situation and improvement of surveying demands, As the university of talent training base, we must undertake the heavy responsibility of training excellent surveying talents for society, therefore, constructing “informatization surveying” practical teaching system is imperative[2][3].

\section{The content of "informatization surveying” practical teaching system}

1. The construction of "Pyramid" practical teaching structure

Using the way of combining in-class with extracurricular training, intramural with extramural training, the demonstration and replication experiments which are as the bottom of pyramid, laying the foundation of training practical ability[4]; the comprehensive and designing experiments, daily trainings and vocational skills trainings of undergraduate research assistants which are as the body of pyramid, training the engineering technology accomplishment of university students; advocating activities that innovative experiments, research assistants participate in research subjects of advisors and join the science and technology innovation competitions which are as the top of pyramid, training innovative top-notch talents of surveying and mapping engineering. Basic practice projects integrate into designing, innovative contents, the comprehensive practice project is not separated from the base, various types of practical projects permeate each other.

2. Establishing the experiment teaching mode of "seriation, three-dimensional, multi-level"

Seriation: Including the seriation of experimental platforms and experimental projects, meeting the diverse needs of students. Three-dimensional: Organically linking the underground, ground and 
aviation, and making students fully grasp how convert aerial images into surface topographic maps, and how transfer the plane coordinate system and elevation of the ground into the underground. Multi-level: According to the experimental objects of different grades and different science classes, constructing the experimental content system of "basic knowledge- skill training- comprehensive practice- applied innovation".

3. The construction of integrative intramural and extramural practical base

In order to realize the "sharing, interaction" of practice and teaching units, using social resources to run schools, the "zero gap" training objective between the basic quality of graduates and social demand standard, establishing a number of practical teaching bases and innovative practical bases of university students with resources integration, full sharing, efficient use[5].

(1) Using the civil air defence works of schools, constructing the practical base of underground engineering surveying in the school, and making the ability of operating instruments of students get sufficient exercise under the shaft.

(2) On the basis of research and demonstration, reconnaissance, overall observation and internal data processing which are controlled by city GNSS in Jiaozuo, completing the construction of practical bases of urban control surveying, and building the first control net of urban construction of Jiaozuo.

(3) In view of the characteristics of the short practical time and few tasks of classrooms, building practical bases with small area and relative concentration in the school, which can set up elementary surveying, topography surveying, line engineering surveying, etc.

(4)The distance between practical bases of Taihang mountains and the school is only 10 kilometers, the geomorphological type is complex, there are mountain districts, hills and plains, which are the ideal place of practicing topographic map surveying.

4. The construction of network practical teaching platform of surveying engineering

The experimental teaching website of surveying engineering is the network platform with back-stage management function which is developed based on ASP technology, which can be as the system platform of publishing demonstration news announcement, and also has the interactive login and management functions of submitting reports, booking experiments, answering questions, etc[6]. This platform sets up the network simulation laboratory, combines with the virtual instrument technology and network technology, constructs the open and long-distance practical teaching system, and meets and supports the construction and implementation of network platform of experimental teaching system of surveying engineering.

5. The reform of practical teaching method and means

Adding case teaching and class discussions to practical teaching methods, combining with specific situation, basing on the teaching method with enlightenment, self-studying, discussion and research, using the easy way, fully mobilizing students' learning enthusiasm, and training their innovative thinking and innovative ability.

6. Perfecting the practical teaching evaluation system of surveying engineering which is based on scientific inspection and reasonable evaluation

Following the integrity, scientificalness and encouragement principles, scientifically evaluating comprehensive quality, professional ability, scientific research ability and moral cultivation of teachers from multiple levels and multiple angles, and providing the advantageous safeguard for practical teaching. At the same time, through the way of teachers and students evaluate each other, timely feeding back the problems which appear or exist in the practical teaching to management departments of schools, promoting the promulgation and implementation of effective policies and measures, and maintaining scientific healthy operation of practical teaching[7].

7. Strengthening quality monitor of the whole course through taking examination and supervision as the means

According to the goal and feature of talent training, making the relevant rules and regulations, establishing and perfecting the quality examination and evaluation index and standard system of practical courses (teaching). Building the teaching supervision committee, which can timely guide and supervise, and feed back related information to related functional departments, so which can 
make the corresponding system adjustment and scheme revise; Through the way of setting up students information men and supervisors, mobilizing every person to involve in quality monitor, Focusing on improving students' innovative quality and practical ability, comprehensively tracking experimental teaching and monitoring the quality, and promoting the update and perfection of modern engineering education practical teaching system.

\section{The practice of "informatization surveying” practical teaching system}

"Informatization surveying” practical teaching system organically combines "modularization" with "individuation", closely links "similarity" with "characteristic", and forms distinct characteristics in inter-disciplinary talents training of engineering courses, at present, practical teaching of surveying and mapping engineering of our school has initially formed unique innovative mode, through the method of "pilot-summary-enlarge pilot-summary-comprehensive promotion", actively and steadily implementing and promoting "informatization surveying" practical teaching system of surveying and mapping engineering, and obtaining good teaching effect.

1. Changing traditional professional practical curriculum setting is depended on the transverse mode of theory courses system, establishing relative independent courses with vertical relation on the foundation of original practical courses, and forming the cross net professional practical curriculum system, realizing the vertical relation and penetration of professional practical curriculum.

2. Constructing the two practical platforms that intramural project simulation and extramural combat training, cultivating the project ability and innovative ability of students, and enhancing the professional teaching quality.

3. Changing the old pattern of distributing and managing resources of the laboratory according to courses. Combining practical resources and realizing the platform sharing of practical teaching and innovative scientific research activities of students, increasing the opportunity of exercising innovative ability of students.

4. Changing the organization form that practical teaching takes the single course group and student class as the unit, and forming cross teaching guide teams and students learning teams with interests.

5. The combination of classroom practical teaching and technological innovation activities improves students' innovative ability. When conducting practical teaching in a classroom, at the same time, systematically organizing technological innovation activities outside the classroom, including open experiments, SRTP project, step by step climbing program, open fund projects of the laboratory, etc.

6. The practical teaching promotes the construction of subjects and majors. Perfect "informatization surveying" practical teaching system promotes the construction of surveying and mapping subjects and majors and the provincial teaching demonstration center of surveying and mapping engineering, quicken the development of surveying subjects and relevant majors.

7. "Surveying innovation and strong practice ability, strong application service innovative consciousness" has becomes the characteristics of surveying major graduates. The open of a large number of comprehensive, designed and innovative practice and experiment items, the establishment and implementation of the practical teaching mode, which optimize students' knowledge structure, the basic skills, engineering practice, application service and innovative ability of students obtain the significant ascension.

\section{Conclusion}

Through the implementation in our school, the overall experimental teaching quality and organization and management standard have obtained huge increase, which comprehensively improve the project and innovative ability of students, and make students have enough competitive power and development power in the graduation, employment and future professional work, which will provide giant promotion function to our school successfully declares the national surveying and 
mapping engineering experimental teaching demonstration center and quality engineering project, and also provide great reference value and demonstration to the development of experimental teaching of the nationwide same engineering schools and the training of innovative talents.

\section{References}

[1] Yang Yuhai. Establishing the evaluation and incentive mechanism to promote the open, sustainable and healthy development of laboratories [J]. Practice technology and management. 2004, 21(2): 1-4

[2] Su Xin. The discussion and research of open management of laboratories [J]. Laboratory research and exploration. 2003, 22(5): 139-139

[3] Wang Xiaodi. The understanding and exploration to the open of laboratories of colleges and universities [J]. Laboratory science. 2005, 41(1): 126-128

[4] Peng Zheng, Jia Houguang. The several problems that laboratory open should note [J]. Practical teaching and instruments. 2005, 22(6): 54-55

[5] Zou Wanling. The new thinking of teaching management: informatization management, not the management informatization [J]. Journal of Guangzhou University (Social science edition). 2006, 5(2): 54-57

[6] Yang Hui, Zhou Yingzhong. The complexity characteristics and enlightenment of class teaching activitiy system [J]. Contemporary education BBS. 2007, (2): 80-83

[7] Guo Fang, Liu Jiehui. The reflection and exploration to practical teaching reform [J]. Journal of Hebei architecture school (Social science edition). 2004, (2): 1-2 